Wilfrid Laurier University

Scholars Commons @ Laurier

3-1-2003

\title{
Cultural Rights and Internal Minorities: Of Pueblos and Protestants
}

Andrew M. Robinson

Wilfrid Laurier University, arobinson@wlu.ca

Follow this and additional works at: https://scholars.wlu.ca/poli_faculty

Part of the Political Theory Commons

\section{Recommended Citation}

Final submission version of the article. The Version of Record is published in the Canadian Journal of Political Science 36:1 (March 2003): 107-127.

This Article is brought to you for free and open access by the Political Science at Scholars Commons @ Laurier. It has been accepted for inclusion in Political Science Faculty Publications by an authorized administrator of Scholars Commons@ Laurier. For more information, please contact scholarscommons@wlu.ca. 
Cultural Rights and Internal Minorities: Of Pueblos and Protestants*

ANDREW M. ROBINSON, University of Western Ontario

Andrew M. Robinson, Department of Political Science, The University of Western Ontario, London, Ontario N6A 5C2; amrobins@uwo.ca

Abstract. This article considers the question: should rights extended to cultural communities to help them preserve themselves include the right to discipline dissident members who violate cultural norms? The case of the Pueblo Protestants is employed to consider two important defenses of cultural rights (revisionist liberal and cultural communitarian) that offer conflicting answers. Both are found unsatisfactory because of their implicit reliance on "cultural monism" (that is, the assumption that individuals identify with only one cultural community). An approach to defining cultural rights is then outlined that avoids this assumption and its application is illustrated with respect to the Pueblo case.

Résumé. Cet article soulève la question suivante: est-ce que les droits, appliqués à des communautés culturelles pour leur propre sauvegarde, devraient comprendre led droit de punir les membres dissidents qui violent les normes culturelles? On aura recours à l'étude du cas des Protestants Pueblos pour étudier deux mécanismes de défence des droits culturels (un libéral révisionniste et l'autre communautarien culturel), qui offrent des réponses conflictuelles. Aucun des deux ne semble satisfaisant en vertu de leur dépendance implicite par rapport au "monisme culturel" (c'est-à-dire la présupposition que les individus s'identifient à une seule communauté culturelle). Ensuite, l'article décrit dans ses grandes lignes une approche qui est applicable à la définition des droits culturels et débarrassée de ce présupposé de monisme. Sa mise en application sera exemplifiée dans le contexte du cas Pueblo. 
Cultural rights have received much attention in political theory. One irony, out of which critics of cultural rights make much hay, is that the very rights that are extended to shield cultural minorities from the effects of dominant majorities can, and have, been used by those very cultural communities to oppress their own internal minorities. For instance, Katherine Fierlbeck has criticized cultural rights on the grounds that they "may reinforce the marginalization of those who are already disadvantaged within that group."i The implication is clear enough. Defenders of cultural rights are hoisted by their own petard--the solution they propose to the marginalization of one group of individuals leads to the marginalization of some other group of individuals. This is a serious charge that cannot be ignored.

The case of the Pueblo Protestants has attracted much attention in the literature because it provides a clear and concrete illustration of this issue. The Pueblo Indians of the south-western United States have been the beneficiaries of special groups rights that have allowed them to preserve a unique way of life. This distinctive culture is reflected in a "theocratic" form of governance that combines elements of native spiritualism and Spanish Catholicism. The internal minority problem had its origin in the decision of some community members to convert to Pentecostalism. When, naturally enough, the converts began to offend social norms by refusing to participate in communal ceremonies and by attempting to convert others, the authorities exercised their powers of self-government to discipline them. This raises an obvious question: should the right to discipline or expel those who violate cultural norms be included among cultural rights? While this article addresses this question by focusing on the Pueblo case, it has obvious implications for similar situations in which sub-national minorities exercise some degree of political authority over their own people. Examples range from a cultural community controlling a regional political unit by virtue of demographics (for example, francophones in Quebec, Inuit in Nunavut), to 
ethnically-defined political units (for example, aboriginal reservations in North America), to control of publicly subsidized minority cultural industries (for example, Welsh-language publishing and the Welsh-language television channel Sianel Pedwar Cymru in the United Kingdom).

The Pueblo case has elicited conflicting responses, even from defenders of cultural rights. Two in particular are worth examination because of their influence, the disparate nature of their conclusions and, as I will argue, because a careful consideration of their shortcomings may point the way to a more satisfactory resolution. One approach, which we will call revisionist liberal, defends cultural communities on the grounds that they contribute to personal autonomy. In conflict, the individual's interest in autonomy must take precedence over any interests of the community. Thus Will Kymlicka, a leading proponent of this view, denies that the Pueblo community should have the authority to discipline its dissident members. ${ }^{\text {ii }}$ A conflicting approach, which we will call cultural communitarian, rests its defence of cultural communities on their potential to contribute to individual self-fulfilment. That is, where conflict arises the individual's interest in autonomy must be weighed against the community's ability to make this contribution. Thus Frances Svensson, a proponent of this view, suggests that the Pueblo communities should be allowed to expel dissidents. ${ }^{\text {iii }}$

This article attempts to advance the debate about the treatment of internal minorities, and cultural rights more broadly, by problematizing the relationship between the individual and the community implicit in these approaches, and by elaborating a revised understanding that may form the basis of a more compelling defence of cultural rights. In brief, it argues that the emphasis revisionist liberals and cultural communitarians place on personal autonomy and community, respectively, leads them to rely upon conceptions of cultural community that cannot recognize the 
complexity of individual self-identity. An alternative approach that allows the conflict between the values of autonomy and community to be transcended is developed by embracing a value that underlies both-- "meaningful life". While no rash promises are made about the ability of this approach to finally resolve the internal minority issue, the article concludes by proposing principles for the design of cultural rights that are more sensitive to the complexity of self-identity.

\section{Two Justifications of Cultural Rights}

The Pueblo Protestant case provides an excellent basis for comparing how revisionist liberal and cultural communitarian defences of cultural rights address conflicts between individual freedom and communal authority. As we shall see, revisionist liberals and cultural communitarians frame the issues very differently because their approaches emphasize different values.

The typical pattern of the conflicts between Protestant dissidents and their Pueblo communities was documented by Florence Hawley in a case study published in $1947 .{ }^{\text {iv }}$ It involved several Pueblo individuals who, having converted to Pentecostalism, felt obliged by their new beliefs to proselytize nonbelievers and to refrain from dancing, drinking, smoking and taking medicines of any kind. This brought them into conflict with a communal authority that considered participation in communal religious dances and deference to the decisions of the chief priest as basic duties. In what appears to be a characteristic pattern, the deviants were reprimanded and then, after repeatedly breaking promises to refrain from the offending activities and to participate in communal dances, were banished from the village and their right to communal lands was revoked.

The central question raised by this case differs subtly, yet significantly, depending upon whether one assumes the revisionist liberal or the cultural communitarian perspective. The revisionist liberal view is concerned with the legitimate claims a community can make on an individual: should village authorities have the right to evict dissidents who refuse to participate in communal practices? 
Conversely, the cultural communitarian is concerned with the amount of deviance a community should be expected to tolerate: at what point should dissidents lose their privilege to participate in the life of the community? As we might expect, these different perspectives, inform contradictory proposals for conflict resolution.

For the revisionist liberal, cultural communities are only valuable instrumentally to the extent that they sustain conditions necessary for the exercise of autonomous choice by individuals. They have no intrinsic value. Thus Kymlicka says that membership in cultural communities provides individuals with "an intelligible context of choice, and a secure sense of identity and belonging, that [they] call upon in confronting questions about personal values and projects."v This supports autonomy because it is through membership in such communities that persons "become aware, in a vivid way, of the options available to them, and intelligently examine their value."vi Thus extending special protection to such communities is justified when it serves "to remove inequalities in the context of choice which arise before people even make their choices." vii

From this perspective, then, the Pueblo Protestants raise questions of religious freedom. Having justified cultural rights instrumentally as a precondition of members' personal autonomy, the revisionist liberal leaves little ground upon which to justify limiting religious freedom for the good of the community. ${ }^{\text {vii }}$ It would be contradictory to include among cultural rights--justified on the grounds that they are a precondition of individual autonomy--the right to limit religious freedom. Kymlicka says that once a cultural community has been protected, it should become a "cultural-marketplace" within which "decisions about which particular aspects of one's culture are worth maintaining and developing [are] left to the choices of individual members." ${ }^{\text {ix }}$ Thus he concludes that the actions of the Pueblo community represent an unjustifiable restriction on religious liberty: "If the goal is to ensure that each person is equally able to lead their chosen life within their 
own cultural community, then restricting religion in no way promotes that. Were the theocracy ended, each majority member of the Pueblo would have as much ability to use and interpret their own cultural experiences as the dissident minority, or, indeed, as members of the non-Indian community."x

The cultural communitarian is led to propose a different solution because she or he presumes that cultural communities have intrinsic value as a natural and enduring aspect of every human's experience. Svensson, for instance, distinguishes the multidimensional group, which has "many interlocking dimensions or facts shared by its members--in an ideal case, for example, language, religion, ethnicity, race and historical experience, "from the unidimensional group, like interest groups or religious communities. About this distinction, she writes, "there is a politically and morally significant difference between the American Medical Association or the National Rifle Association on the one hand, and the French-speakers of Quebec or the Amish in Pennsylvania on the other." The multidimensional group is special because it "is, in social-psychological terms at least, semi-autonomous and its members more or less permanently isolatable," and it helps its members attain self-fulfilment by contributing to identity and defining "needs and desires and the ways to achieve them."xi These characteristics are of such significance, she suggests, that these groups should be recognized in liberal-democratic theory alongside individuals and states. ${ }^{\text {xi }}$

It will be useful to consider how Pueblo communities represent multidimensional groups, in terms of interlocking dimensions and in shaping values. Having been in almost continuous contact with Europeans in one form or another (Spain, Mexico, United States) since first encountering the Spanish in 1540, ${ }^{\text {xii }}$ the Pueblo have developed a culture that, while infused with many European values and ideals, remains distinct. Both the traditional Pueblo spiritualism of the pre-contact community and the innovations that evolved in the face of Spanish attempts to impose Catholicism 
and Spanish civil government contributed to the development of communal traditions that encourage the values of harmony, unanimity and duty while downplaying individual freedom.

These values no doubt have their origin in the Pueblo's being a sedentary people in an arid part of the world whose survival depended upon complex irrigation systems and the capricious whims of nature. In such circumstances, it is not surprising that they developed a markedly non-personal, communal, religion that focused on the reciprocal relationship between the community and nature in which "man performs rites and ceremonies and nature responds with the essentials of life, withholding the bad." ${ }^{x i v}$ When combined with the "conviction that it is the responsibility of all to work together in secular and religious activities to keep the universe functioning smoothly," it is understandable that the Pueblo would develop conceptions of virtue and vice like those traditionally held by the Tewa Pueblos, according to whom "negative attributes such as unco-operativeness, moodiness, aggressiveness, and uncontrolled anger [were] considered violations of the ideal of unanimity concept, [and] generosity, hospitality, deference to the old, and a mild and conforming demeanor [were] accorded high value."

The emphasis the Pueblo placed on unanimity and harmony appears to have been reinforced by their experience of the Spanish. On one hand, many Pueblo found no inherent contradiction in sincere adherence to Catholicism, while continuing to practice of their native religion. Each religion addressed different concerns: Pueblo religion dealt with the here and now (rainfall, illness, warfare, communal harmony); Catholicism dealt with life after death. Thus, "the church, like the Kiva [the native religious building], is an important religious structure where the worship of two sets of deities are [sic] conducted separately."xvi

On the other hand, the refusal of the Spanish authorities to accept dual religious loyalties necessitated a collective response that could not have succeeded without strict communal 
compliance. In particular, it required a strict compartmentalizing of religious life:

Those dances and rites that aroused no opposition or displeasure from the non-Indian population were given openly and frequently, indeed as if these activities were all that remained of the indigenous culture. But behind closed doors, in heavily guarded areas, there was the performance of another set of complex rites shorn of all borrowed elements from the intruding culture. These were the ceremonies that in all their pagan glory offended Spanish civil and church authorities. ${ }^{\text {xvii }}$

Survival of the Pueblo religion required that compartmentalization be extended to Spanish civil institutions. The traditional Pueblo social organization, which required civil institutions to control religious as well as civil functions, had been sustained by the practice of having secular officers of the civil government mask "the identities and activities of the native officers who are additionally concerned with ceremonial matters." In effect, they carry out the decisions of a "de facto governing group" of ceremonial leaders constituted by "a hierarchy of native 'priests'."xviii This has been described as "theocracy" or "quasi-theocracy."xix Maintaining such a compartmentalized existence could only have reinforced the traditional values of harmony and unanimity and would have left little room for the tolerance and individualism so characteristic of the wider American community.

There seems little question, then, that the Pueblo, distinguished as they are by their religious, political and economic institutions and by their cultural values, constitute cultural communities in the sense intended by cultural communitarians.

From the cultural communitarian perspective, the Pueblo Protestants are not individual deviants so much as bearers of the values of a foreign culture. In other words, the conflict they create is not viewed as occurring within the Pueblo community but, rather, between representatives of the American cultural community and the Pueblo cultural community. From this perspective, the degree 
of difference the dissidents represent could only be accommodated within the community by undermining the values that define it. Thus for Svensson, the Pueblo case concerns whether the values of the minority community (communal participation and quasi-theocracy) or the dominant community (Protestantism and separation of church and state) prevail. Having decided that the Protestant converts have assumed the values of the dominant society, she says that there remains an "appeal" of last resort, an outlet for them--merger with the dominant society. If the rules of the dominant society are imposed upon the minority community across the board, the minority community has no place left to go, no refuge in which its values and priorities can be recognized. Of two possible injustices, the former appears to be more acceptable than the latter, since it preserves the maximum openness of opportunity to members of both dominant and dependent communities. ${ }^{\mathrm{xx}}$

Thus cultural communitarians and revisionist liberals are compelled by their arguments to make very different recommendations. For the revisionist liberal, the religious freedom of the dissidents outweighs the claims made by the community. Conversely, the cultural communitarian finds that the threat posed by the dissidents to the community's way of life justifies their expulsion. I believe that the differences in the assumptions that inform these conclusions are so fundamental that there is little hope of advancing the cause of cultural rights by continuing the debate. Instead I propose to advance the discussion by shifting the focus from conflicting justifications to complementary underlying values. In the case under discussion, we can begin by focusing on something they have in common--their accounts of communities that deserve protection.

\section{Cultural Monism}

While the revisionist liberal and cultural communitarian approaches offer different justifications for cultural rights, they share an understanding of the nature of communities that can warrant such 
treatment. This section will develop two points. The first is that both approaches are driven by their inner logic to assume that only communities whose members can be distinguished from members of other communities can merit protection. This assumption will be called cultural monism. The second is that the assumption of cultural monism is problematic. In particular, it leaves those who invoke it with precious little resources to make sense of, or even acknowledge, the complex self-identities epitomized by people like the Pueblo Protestants who simultaneously identify with aspects of more than one community. Unlike the cultural communitarian's commitment to cultural monism, which is clearly illustrated by Svensson's idea of the multidimensional group (a community with "many interlocking dimensions" whose "members more or less permanently isolatable"), the relationship between revisionist liberalism and cultural monism requires more explanation.

The revisionist liberal adopts cultural monism as a strategy for translating claims about personal autonomy and community as a "context of choice" into a defence of special cultural rights. This is attempted by suggesting that there is a special relationship between the individual, cultural community and personal autonomy; that is, by claiming that one's capacity for personal autonomy is somehow circumscribed by one's community. Kymlicka does this in two moves. First, he ties the capacity for autonomy to a particular community by suggesting that, as contexts of choice, cultural communities make individuals aware "of the options available to them." Second, he plays down the possibility that individuals might sustain their autonomy by abandoning unviable communities and joining other more viable ones by suggesting that, while possible, this choice is "rarely easy"' In fact, he suggests that it is unreasonable to expect people to renounce membership in their particular cultural community. ${ }^{\mathrm{xxi}}$

There are several reasons why only communities that meet the test of communal monism could satisfy these requirements and, thus, qualify for cultural rights. This suggests two 
characteristics that would necessarily limit the range of communities that could qualify: if a community is to present enough options to sustain lives of autonomous choice, it must be fairly large and diverse; and, as a context of choice, a community must circumscribe its members' normal capacity to exercise choice. Thus it must transcend more limited communities that, under normal circumstances, do not make exclusive claims on their members' self-identities (family, religion, ethnicity). Such non-exclusive communities cannot constitute contexts of choice and, thus, cannot merit cultural rights. This claim to exclusivity is also important because without it the revisionist liberal defence of special rights would collapse: if an individual simultaneously belonged to two or more cultural communities, the loss of any one of them would not deprive him of access to $a$ context of choice. Thus there would be no inequality in access to contexts of choice to be addressed. It is hardly surprising, then, that Kymlicka describes the type of community that is consistent with his argument as one which provides its members with meaningful ways of life across the full range of human activities, including social, educational, religious, recreational, and economic life, encompassing both public and private spheres. These cultures tend to be territorially concentrated, and based on a shared language.... [and] involve not just shared memories or values, but also common institutions and practices. ${ }^{\text {xxii }}$

Thus the cultural rights defended by both revisionist liberals and cultural communitarians apply to communities that exhibit cultural monism.

The value of cultural monism is that once it is assumed that there are such things as cultural communities into which people can be neatly slotted, many vexing and troubling problems seem to disappear. For the revisionist liberal, once it has been determined that an individual is a member of a particular cultural community, then, his chosen way of life must be tolerated, even if it is offensive 
to the values that define the community. ${ }^{\text {xxiii }}$ Conversely, for the cultural communitarian, if it can be determined that a dissenting individual bears the values of a different community, then it is permissible for him to be ostracised.

The case of the Pueblo Protestants poses a serious threat to the assumption of cultural monism because it challenges the very idea of cultural exclusivity. The reason being that they chose, Pentecostalism, which originated outside the Pueblo community within the black underclass of urban New Mexico. ${ }^{\text {xxiv }}$ If people raised in Pueblo communities are able to make meaningful choices from options within the wider American culture, then the Pueblo community does not appear to circumscribe its members' identities in the way that cultural monism requires. This creates different, but interrelated, problems for revisionist liberals and cultural communitarians.

For the revisionist liberal, it challenges the assumed connection between cultural community and context of choice upon which the defence of cultural rights depends. Once it is admitted that the context of choice for Pueblo Indians includes the options available in the wider American culture, it is not clear that there is a unique Pueblo context of choice to protect. This problem is compounded by the inability, or unwillingness, of the revisionist liberal to define either the cultural community or its boundaries. This reluctance arises naturally enough, given the revisionist liberal's desire to promote personal autonomy--any such definition would necessarily restrict the choices a person could make while remaining a member of the community. This is reflected in Kymlicka's refusal to seriously consider the possibility that by converting to Pentecostalism the dissidents might have affected their status as Pueblos.

In such cases, where the new identifications are clearly at odds with the values of the community, the reluctance to define boundaries gives rise to a troubling epistemological problem: without some definition of the boundaries of the cultural community, how are we to know if its 
members' ability to "use and interpret their cultural experiences" has been preserved or destroyed? If such a radical change as ending the practice of theocracy so as to satisfy a dissident minority would not undermine this ability, it is unclear what changes would. Further, the problem cannot be avoided by defining membership in terms of descent -- that is, the claim that children of Pueblos are Pueblos. While this may appear to provide a clear definition of membership without restricting individual choice, it would actually only create new problems, since even a theory of cultural monism must accept that people can and do leave their community of birth and assimilate into other communities. To continue to treat such emigrants as members of an original community that receives special protection would be doubly unjustified. On the one hand, it would be unfair for those who assimilated into the dominant community to continue to enjoy special rights unavailable to those born into it. On the other, having assimilated into the dominant community, the continued participation of these people in the protected community could pose a threat to its survival. Thus the need for definition re-emerges, this time a definition of what it means to have left a community.

Unlike the revisionist liberal, the cultural communitarian is willing to define communal boundaries. By defining these boundaries according to the assumptions of cultural monism, however, the cultural communitarian has difficulty dealing with the challenge posed by the Pueblo Protestants. In particular, he cannot treat it as a conflict within the community because his refusal to recognize the claims of unidimensional communities has left him in no position to give any independent weight to the Pentecostal community. In the world of the cultural communitarians, only the contribution of cultural communities to individual self-fulfilment warrants special treatment. Thus the cultural communitarian must deny the complexity of Pueblo Protestant self-identities--they are either Pueblos or mainstream Americans.

But why, given that cultural communitarians justify cultural rights on the contribution 
communities make to self-fulfilment, should cultural communities be privileged over such unidimensional groups as kinship associations or religious sects? As it turns out, Svensson's reasons are more pragmatic than principled, and none answers our critique. The first is that they resemble interest groups which already receive recognition. This does not acknowledge that interest groups are not accorded anything approaching cultural rights. The second is that the complexity arising from the fact that individuals usually belong to many such groups would quickly lead to the reassertion of "the principle of overriding individual rights." While the problem of complexity might justify the refusal to extend cultural rights to unidimensional groups in particular cases, it cannot justify a blanket refusal to consider their claims. The third reason is that the dimensional complexity of the multidimensional group, unlike unidimensional groups, "produces such characteristics as endurance over time, stability of identity, systemic interdependence, and relative autonomy, and these in turn play a crucial role in qualifying groups for special status while avoiding the problem of open-endedness." ${ }^{x x}$ This ignores the fact that many unidimensional groups exhibit the requisite stability and that many multidimensional groups do not. What should matter is the stability and importance of the group, not its dimensionality. While these reasons can certainly justify the rejection of the claims of unidimensional groups on a case-by-case basis, they do not add up to a principled justification for the rejection of such claims altogether. To reiterate, by insisting on limiting special recognition to cultural communities, the cultural communitarian is unable to recognize the possibility that the Protestants have constructed complex self-identities that depend upon sustaining identifications with both the Pueblo and the Pentecostal communities.

Thus the case of the Pueblo Protestants reveals problems with the assumption of cultural monism that neither the revisionist liberal nor the cultural communitarian approach is able to overcome. Both must deny the complexity of their self-identities. On the one hand, this leads the 
revisionist liberal to take an ambiguous stance on the boundaries of cultural communities, and thus extend the scope of contexts of choice beyond credibility. On the other, the cultural communitarian responds by limiting special recognition to cultural communities, a move that appears inconsistent with the idea that communities that contribute to individuals' self-fulfilment warrant special recognition.

\section{An Alternative Approach}

The key move in this proposal to advance the debate on cultural rights is to reject the assumption of communal monism and thus to recognize the importance of a wider variety of communities than those defended by revisionist liberals and cultural communitarians. This, we shall see, requires a different account of the relationship between individuals and communities, one that transcends, without rejecting, the revisionist liberal's emphasis on personal autonomy and the cultural communitarian's emphasis on community.

We begin this by considering the reasons Kymlicka gives for the importance of membership in cultural communities: i) they provide members with meaningful options as found in "contexts of choice"; and ii) they support "a secure sense of identity and belonging, that [members] call upon in confronting questions about personal values and projects."xxvi This suggests two conceptually distinct functions that a community may perform: it can provide its members with: i) options to choose from; or ii) standards to choose by. Communities that provide options contain the options from which an individual might meaningfully choose. Communities that provide standards act as a "primary focus of identification" and inform individuals' decisions about how to act and which purposes to pursue. By refusing to define the character of cultural communities, the revisionist liberal, I suggest, overemphasizes the role of communities in providing options, and does not put sufficient weight on their ability to provide standards. 
If the point about providing standards is unclear, consider Melissa Williams' comment regarding Kymlicka's treatment of the Pueblo, that "it strikes me as a tricky bit of surgery so neatly to separate religion from culture."xxvii If we consider the role of the Pueblo religion, as part of the wider Pueblo community, in providing standards of choice, it is unreasonable to treat it as simply one option among the many that the Pueblo community supports. Rather, we must recognize it as a source of values and beliefs that support standards that inform people's choices.

The idea that communities provide standards of choice can be illustrated with Joseph Raz's idea that different societies are distinguished by their social forms. Social forms consist of "shared beliefs, folklore, high culture, collectively shared metaphors and imagination, and so on." ${ }^{x x v i i i}$ That one society is autonomy-enhancing and another is traditional, is, in Raz's view, inherent in, not independent of, each society's social forms: "The conditions of autonomy do not add an independent element to the social forms of a society. They are a central aspect in the character of the bulk of its social forms." ${ }^{\text {xxix }}$ Consider the social form of marriage: in autonomy-enhancing societies marriages are chosen, in traditional societies they are pre-arranged. ${ }^{\mathrm{xxx}}$ Similarly, the social forms associated with the Pueblo community and its religion are inherently communal. They convey the importance of communal participation in ceremonies and warn of dire consequences if this fails to occur. To make the practice of such social forms voluntary is not simply to change the way options are exercised, but to undermine their ability to sustain the standards that define them. This could only be considered to sustain the Pueblo's ability to "use and interpret" central aspects of their cultural experience if one ignores the values and standards that the experiences embody. This distinction is more difficult to overlook if one assumes the perspective of communities as embodying "standards to choose by".

In the remainder of this article I will consider the implications of basing a defence of cultural 
communities on their ability to provide their members with such standards. In order to do so, I suggest, communities must connect their members to contexts of values (shared beliefs, values, projects, and so on) that inform, sustain or promote significant purposes. Thus, for example, communities as contexts of values might provide people with a sense of goals that are worth attaining, personal qualities that are worth developing or overcoming, character types that are worth admiring, lifestyles and careers that are worth pursuing and, more generally, ways to understand the world. ${ }^{\text {xxi }}$

Emphasizing contexts of values, rather than contexts of choice, is important because it enables a rejection of communal monism and, thus, a recognition that, in addition to cultural communities, communities that exist within and across cultural communities (familial, religious, ethnic, linguistic) may make contributions to meaningful lives in ways that deserve special recognition. Thus, in the Pueblo case, we can discuss the Pueblo and Pentecostal communities without having to equate membership in the Pentecostal community with membership in the wider American community.

Whereas revisionist liberals emphasize the contribution of contexts of choice to personal autonomy, and cultural communitarians assume that only cultural communities contribute to self-fulfilment, the approach here would defend communities that function as contexts of values on the basis of their contribution to an underlying interest in leading meaningful lives (lives characterized by the pursuit of subjectively significant purposes). Such lives have two requirements--the freedom to form significant purposes and the freedom to pursue them--both of which may, under some circumstances, justify the extension of special rights to communities. A purposes, a community may warrant special rights where it sustains unique forums within which particular significant purposes may be pursued. For example, some purposes may only be able to be 
pursued within a particular community, ${ }^{\mathrm{xxxii}}$ others may only be able to be pursued collectively. ${ }^{\mathrm{xx} x i i i}$

To understand the implications of this approach as it pertains to the freedom to form purposes and, later, to the Pueblo Protestants, I shall outline a brief account of the model of self-identity and agency that follows from it. ${ }^{\text {xxiv }}$ In this view, self-identity consists of the entire range of a person's identifications with communities, as well as the particular way in which he or she understands these identifications to relate to each other. Such identifications are formed either through subtle processes of socialization (being raised in a Pueblo community), or through conscious acts of choice (converting to Pentecostalism). While one would normally expect individuals to make such identifications with many communities, this is not necessary.

Given this conception of self-identity, agency takes one of two characteristic forms. In one, the agent treats certain aspects of his or her self-identity as given when forming a purpose and determining how best to pursue it. ${ }^{\mathrm{xxv}}$ In the other form, the agent makes self-identity the object of deliberation, usually in response to meaning-threatening dissonance. This can arise when deliberation reaches conflicting or contradictory conclusions that reflect underlying inconsistencies in the contexts of values with which the person identifies. Such dissonance is resolved, if indeed it is resolved, either by transforming self-identity (by prioritizing, compartmentalizing, rejecting, reinterpreting or replacing identifications) or by removing the cause. In this, the driving force is the need to sustain meaning.

At this point, I seem to have constructed an argument against cultural rights. Recognition of the potential complexity of self-identity appears, as Svensson feared, to recommend the reassertion of "the principle of overriding individual rights." If self-identity can be as fluid as described, it seems reasonable to expect people whose communities are threatened to simply identify with some other, more viable, community. This is not unlike a conclusion reached by Chandran Kukathas. He rejects 
cultural rights, even though he recognizes that "the breakdown or disintegration of such communities" might lead to "social dislocation or anomie," and argues instead for a strong account of freedom of association defined as the freedom "to form communities and to live by the terms of those associations." ${ }^{x x x v i}$ If the approach being developed here is to have any credibility, it must explain why we are not compelled to follow Kukathas down this path.

One of Kukathas' reasons for rejecting cultural rights is that he thinks it would do no great harm since "groups are not fixed and unchanging entities in the moral and political universe."xxxvii While my approach is certainly consistent with the suggestion that self-identity can be fluid, fluidity is not absolute. Rather, we can also acknowledge that self-identity may also be fragile. While it can exhibit fluidity when people voluntarily alter their identifications, self-identity can also exhibit fragility when people are involuntarily deprived of identifications that support their ability to form or pursue significant purposes. This can happen when a person is removed from a community or when the community is destroyed. This is especially so where the nature of a person's commitment to identifications makes it unthinkable to replace them with any of the available alternatives. ${ }^{\text {xxviii }}$ Thus, having been deprived of some community or communities, and been unable to identify with any viable alternatives, a person could be left incapable of forming or pursuing any significant purposes at all. The recognition in this approach of both the potential fluidity and fragility of self-identity is important because it can explain the existence of people who need access to their particular communities and of people who are able to move effortlessly between cultures. It also enables recognition that in some circumstances people may require special protection for their communities without having to invoke the assumption of cultural monism.

By rejecting cultural monism, and subsequently subsuming cultural rights within a broader category of rights based on communities that embody contexts of values, this approach appears 
better able to deal with the plight of the Pueblo Protestants. In particular, it can deal directly with a genuine conflict of interest which, to be fair, neither the revisionist liberal, nor the cultural communitarian, denies. On the one hand, it allows, unlike cultural communitarians, acknowledgement that the Protestants have constructed meaningful lives based on identifications with two contexts of values and that the meaningfulness of their lives, as they have constructed them, may depend upon having access to both. On the other hand, it permits recognition that, unlike the revisionist liberals, the dissidents' attempts to live in accordance with their new values may threaten the survival of the wider Pueblo community upon which they and many others depend.

Ultimately, the value of this approach lies in its ability to provide a new perspective from which to consider conflicts over cultural rights. While there is certainly nothing new in an attempt to reconcile liberal and communitarian perspectives on cultural rights, I believe this approach does

break new ground in two ways. ${ }^{\text {xxix }}$ First, as we have seen, it develops a theoretical model to show how the values underlying these perspective may be related and, in some respects, complementary. Second, and this is the subject of the next section, it informs the development of general principles for applying these insights to concrete debates.

\section{Reconciling Perspectives}

In this section I suggest some general principles for the design of cultural rights that reflect the insights developed above and illustrate them with reference to the Pueblo case. ${ }^{\mathrm{xl}}$ Given the model of agency and account of self-identity, any principles must respect three important insights: first, individual members of a cultural community share a collective interest in the preservation of the community as a context of values; second, they also share an individual interest in maintaining maximal freedom to define their self-identities; and, third, both the nature of the communal context of values and the self-identities of individuals are open to change over time. Further, since neither of 
these interests is justified absolutely, but, rather, both are justified by their contribution to the underlying value of meaningful life, in circumstances where they come into conflict, resolution should be sought by trying to reconcile individual and collective interests to show equal respect for everyone's interest in leading meaningful lives, not by allowing one set of interests to trump the other.

It is in the development of these principles, I believe, that the focus on communities as contexts of values really demonstrates its usefulness. Unlike communities defined, for instance, in terms of the practice of particular historical traditions, contexts of values cannot be protected directly because they have no independent existence of their own. Rather, they exist in the minds of those who share them and they are reflected in the projects that they inspire. Thus cultural rights must be designed to preserve the underlying conditions without which the context of values could not exist: for example, relationships, processes of socialization and ways of life.

This focus on underlying conditions, rather than on particular values or traditions, is crucial because it encourages design of general principles to govern cultural protection that would generate creative tensions which, I believe, offer the best hope for reconciling individual and collective interests. I suggest four general principles, two for the design of communal protection and two for the definition of communal membership, which I believe would preserve what is most valuable in cultural communities while leaving maximal room for individuals to define their self-identities.

Two general principles for the design of protection follow from the requirement that it be consistent with respect for meaningful life. The first is that it be minimal. Protection is minimal when it is no more than necessary to sustain the community as a context of values and to exclude those whose beliefs or purposes are so at odds with those values that their inclusion would pose a serious threat to its survival. Such protection sustains a space within which the traditions of a community can be carried on without predetermining which particular projects or purposes will be favoured over the 
long run. Thus demands inspired by a context of values, but which do not relate directly to its survival, must fend for themselves.

With respect to the Pueblo, two underlying conditions seem especially important: communal control of traditional homelands and village self-government. Preservation of the integrity and communal ownership of traditional homelands would support Pueblo contexts of values in a number of ways. It would enable communities to maintain a concentration of members sufficient to sustain communal languages and other traditional practices: it would guarantee members access to sacred sites which express and affirm their beliefs; it could permit expression of the value of "communal obligation" in duties such as working on the communal dikes and pastures. And, perhaps most importantly, it could sustain a separate space within which children could be socialized as Pueblo.

Village self-government is important as an expression of communal values and as a bulwark against "American" culture. Many Pueblo have argued that their traditions of self-government express and embody distinctive values that would be undermined by rights that are widely accepted in the wider American community. For instance, it has been suggested that "one man, one vote" elections could undermine the legitimacy of those Pueblo governments whose authority is derived from traditional religious beliefs, and, as well, that the behaviour required to succeed in competitive elections is inconsistent with the value of "harmony between the individual, and his social institutions." $x$ li Together, communal control of homelands and self-government could allow a Pueblo context of values and the traditions within which it is embodied to flourish and to continue to develop.

A second principle governing special protection is that it should be impermanent. Since protection is only warranted where it is required to preserve the community as a context of values, and where its members rely on it to sustain meaning, it can only be justified for so long as it is needed. 
This will surely disappoint those who consider this principle inconsistent with the desire of cultural minorities to ensure the survival of their community in perpetuity. ${ }^{\text {xlii }}$ While this approach cannot ensure the survival of communities through future generations, I do not think that it should count against this principle. The impermanence principle simply reflects the fact that some individuals, in their pursuit of meaningful lives, will choose, and should be free to choose, to reject inherited identifications. Thus the ability of people to ensure their community's survival must be limited to their efforts to reproduce this desire in their young.

How impermanence is incorporated into cultural protection will depend upon circumstance. It might be made explicit, say, by requiring community members to express periodic support for the protection. For example, the continuation of communal land ownership or village self-government might be made subject to approval by some specified majority in a vote. This would allow members to choose not to renew protection if they found it unnecessary or too burdensome. In other cases, impermanence might be implicit. For instance, were people to stop purchasing subsidized cultural products, support would simply fade away.

These first two principles presuppose the ability to define the boundary of the community or, more specifically, to decide who belongs. Without some definition of membership it would be impossible to know who should have access to protected cultural sites or who has a right to participate in decisions about retaining them. Two principles for governing the definition of membership criteria also appear to follow from our approach.

One principle is that members must be free to exit the community. This is similar to the impermanence principle in that it makes membership impermanent for individuals. Freedom of exit is valuable for a number of reasons. First, it reflects the potential fluidity of identity--respect for meaningful life requires the accommodation of people who choose to end their association with 
particular communities. Second, freedom of exit allows respect for fluidity without undermining the ability of the community to sustain a context of values that others continue to value. This is important because a decision to leave a community does not, in itself, prove that the community is no longer valued by others. Thus while ensuring freedom of exit will probably have a transformative effect on some communities, ${ }^{\text {xliii }}$ it need not undermine their ability to survive as contexts of values.

A second principle governing the definition of membership is that it should involve some obligation that demonstrates reliance upon, and commitment to, the community as a context of values. This could be monetary (for example, requiring members to buy subsidized cultural products) or non-monetary (membership may require a willingness to fulfil communal duties). These could be effected by requiring communities to create membership criteria, including definitions of rights and duties. ${ }^{\text {xliv }}$ This should help to ensure that only those who really rely upon the community seek membership; and assuage the concerns of members who fear harm to the community from free-riders, and those of non-members who may resent the expense of supporting cultural rights that others experience as a costless benefit. In the case of the Pueblo, membership criteria could be logically related to the minimal bases described above (communal control of traditional homelands and village self-government).

These principles should create competing tensions that will respect both the collective interest in preserving the community and the individual interest in retaining flexibility. The establishment of minimal protection and obligations of membership should prevent individuals from taking action that would put the community at risk. With such criteria, the Protestants would have to make a choice. They could remain in the community, comply with its rules and obligations (including, perhaps, some form of participation in communal dances), practice their Pentecostal beliefs off-reserve or in private, and work for change over the long term. Or they could exit the community, publicly practice their 
Pentecostal beliefs and, perhaps, enjoy limited privileges of participation in the community. This sustains equal respect for meaningful lives because, however the Protestants chose, their decision would reflect their personal assessment of the relative importance of each community to their lives. The option this rules out is unilateral alteration of the nature of a community that continues to provide meaning for the majority of its members.

If the requirements that protection be minimal and impose obligations require individuals to show respect for the collective interest in preserving the community, the principles of impermanent protection and freedom of exit should put competing pressure on community leaders to respect the interest of individuals in maintaining freedom to define their identities. Since the benefits to be derived from contexts of values presuppose the existence of a community, the fact that people are free to reject their membership (communally or individually) should compel communal leaders to refrain from imposing particularly narrow or restrictive conceptions of the community. This is made more likely by the fact that formalized membership codes make such conceptions more transparent and, thus, open to criticism and debate.

I believe this is a more satisfactory solution than the communitarian approach of simply allowing the community to expel dissidents, or the revisionist liberal position that the community should accommodate almost any new found identifications. It forces both dissidents and traditionalist leaders to recognize that their real choice is often not between their ideal conception of the community and one they think is flawed, but between having access to a community that does not meet all of their needs and no community at all. A community, at least one composed of human beings, is always a work in progress and a product of compromise. It is a willingness to participate, and a commitment to keep it going, that ultimately separates members from non-members.

An example, albeit an imperfect one, of how this might work in practice is provided by 
Dozier's discussion of the Santa Clara pueblo. ${ }^{\text {xlv }}$ In 1894 the Indian Agency in Santa Fe recognized a "conservative" faction in the pueblo as the de facto government. This was opposed by a "progressive" faction that, among other things, was against involuntary participation in communal dances, refused to participate in the repair of dikes where it only benefited a few, and judged some native customs by Catholic moral standards. Despite their differences, however, the dissidents continued to act in ways consistent with the preservation of the community. In particular, they showed respect for the Pueblo "values of unanimity and the need to express such values through ceremonial activity." Rather than secede and found a new village, which was no longer an option, the dissidents chose to "be in the pueblo but not of it." In practice, this meant that they participated in public works when they found them acceptable, and openly defied the governing faction when they did not. Overall, while their actions disrupted the functioning of the community, they were careful not to completely undermine it. The schism was repaired in 1935, when the factions agreed with an Indian Agency proposal to adopt a written constitution and an elective form of government. This resulted in a de facto separation of church and state.

Two aspects of this are especially worth emphasizing. First, while the village ended up in a situation similar to that advocated by revisionist liberals, the route by which they arrived at it was very important. Instead of moving immediately to a liberal compromise, a period of time elapsed (41 years) during which people could reorient their self-identities and reinterpret their identifications. This enabled the villagers to make radical changes in their community without destroying it or themselves. Despite its imperfections, this example draws our attention to the importance of letting people develop their lives and communities in ways that are meaningful to them. As Ralph Linton has noted, when changes in the ways of a community reflect the voluntarily choices of its members, "no element of culture will be eliminated until a satisfactory substitute has 
been found.... there will be no point in the process of culture transfer where techniques for satisfying all the group's needs are not present." Where changes are involuntary, however, the results can be "catastrophic" since the "normal process of retention of old elements until satisfactory substitutes have been found is inhibited. The result is a series of losses without adequate replacements. This leaves certain of the group's needs unsatisfied, produces derangements in all sorts of social and economic relationships and results in profound discomfort for the individuals involved."xlvi A second significant aspect of this is that it suggests, contra the cultural communitarian approach, that while respect for community may ultimately require the expulsion of dissidents, attempts to provide maximal room for them while preserving the community are not entirely futile. Thus the dissidents at Santa Clara provide an example of how to express disagreements, even fundamental ones, while continuing to co-operate for the survival of the shared community and its core values.

\section{Conclusion}

This article has tried to advance the debate about cultural rights by developing an approach based on an essential interest in meaningful life. While no one would pretend that, if implemented, this approach would put an end to all conflict internal to cultural communities, the emphasis it places on meaningful life suggests that we might improve upon revisionist liberal and cultural communitarian approaches by transcending rather than rejecting their assumptions about the importance of personal autonomy and community. In particular, it holds out the possibility of taking a principled approach to the design of special cultural protection that is sensitive to the complexity of self-identity and the related risks of marginalization. In so doing, it offers to accommodate greater diversity than cultural communitarians could allow and provides clearer definitions of community and membership than revisionist liberals would provide. 


\section{Footnotes}

* An earlier version of this article was presented at the 1999 annual meeting of the Canadian Political Science Association. The author would like to thank the panel at the CPSA meeting, Richard Vernon and the JOURNAL's anonymous reviewers for their useful comments.

${ }^{\text {i }}$ Katherine Fierlbeck, "The Ambivalent Potential of Cultural Identity," this JOURNAL 29 (1996), 21.

ii See Will Kymlicka, Liberalism, Community, and Culture (Oxford: Clarendon, 1989), and Multicultural Citizenship (Oxford: Clarendon, 1995).

iii See Frances Svensson, "Liberal Democracy and Group Rights: The Legacy of Individualism and Its Impact on American Indian Tribes," Political Studies 27 (1979).

iv Florence Hawley. "The Keresan Holy Rollers: An Adaptation to American Individualism," Social Forces 26 (1947-1948), esp. 273-74. This pattern of conflict became especially prominent on two occasions. On the first, several Pueblo Indians went to court claiming that the governing body and governor of their village had "subjected them to indignities, threats and reprisals because of their Protestant faith." The court dismissed the case on the ground that it had no jurisdiction (Toledo v. Pueblo de Jemez, 119 F. Supp. 429-430). On the second, a US Senate subcommittee heard submissions on a bill to exempt the Pueblo from the Indian Bill of Rights (which had become law in 1968). Many Pueblo feared that the Bill would lead to the disestablishment of their theocratic institutions and prevent the eviction of Protestants. US Senate, Hearings before the Subcommittee on Constitutional Rights of the Committee on the Judiciary of the United States Senate, Amendments to the Indian Bill of Rights. First Session, April 11, 1969 (Washington, D.C.: Government Printing Office, 1970).

${ }^{v}$ Kymlicka, Multicultural Citizenship, 105. 
${ }^{v i}$ Kymlicka, Liberalism, Community, and Culture, 165.

vii Ibid., 190.

viii I say few, because Kymlicka does recognize "that there can be some legitimate restrictions on the internal activities of minority members, where those activities would literally threaten the existence of the community." Liberalism, Community and Culture, 199 (my emphasis).

${ }^{\text {ix }}$ Kymlicka, Multicultural Citizenship, 113.

${ }^{\mathrm{x}}$ Kymlicka, Liberalism, Community, and Culture, 196.

xi Svensson, "Liberal Democracy and Group Rights,” 434-36.

xii Ibid., 421-22.

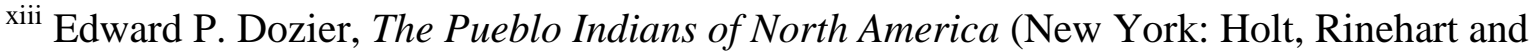
Winston, 1970), 43. Where not otherwise noted, this is the source of the following discussion of Pueblo history and culture.

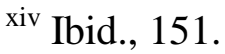

${ }^{x v}$ Edward P. Dozier, "Factionalism at Santa Clara Pueblo," Ethnology 5 (1966), 174-75.

${ }^{x v i}$ Dozier, Pueblo Indians, 50, 67.

xvii Ibid., 75 .

xviii Ibid., 68.

${ }^{\text {xix }}$ Kymlicka, Liberalism, Community, and Culture, 196; Svensson, "Liberal Democracy and Group Rights," 431.

${ }^{\mathrm{xx}}$ Ibid., 437. While Svensson believes there may be cases where the claims of individual rights outweigh group rights, this is not one of them, 436 .

xxi This, he says, is not a claim "about the limits of human possibility, but about reasonable 
expectations." Kymlicka, Multicultural Citizenship, 86.

xxii Ibid., 76.

xxiii Barring, of course, the possibility that his inclusion will result in the vast majority of the community ending up "dead, or in jail, or on skid row." Kymlicka, Liberalism, Community \& Culture, 170.

xxiv See Hawley, "The Keresan Holy Rollers."

${ }^{x x v}$ Svensson, "Liberal Democracy and Group Rights,” 434-35.

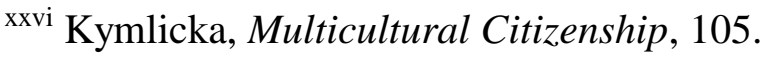

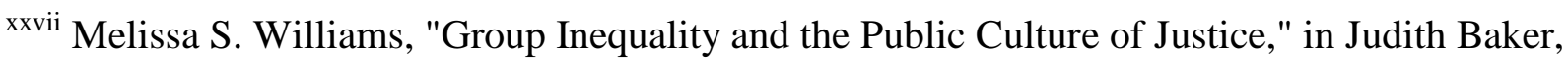
ed., Group Rights (Toronto: University of Toronto Press, 1994), 39.

xxviii Joseph Raz, The Morality of Freedom (Oxford: Clarendon, 1986), 311.

${ }^{\text {xxix }}$ Ibid., 394,

xxx Ibid., 319.

${ }^{x x x i}$ My thinking here is influenced by Taylor's idea of "moral frameworks" that give their members purpose and direction. Charles Taylor. Sources of the Self: The Making of the Modern Identity, (Cambridge: Harvard University Press, 1989), chapt. 2.

${ }^{\text {xxxii }}$ For example, Raz suggests that it is impossible to pursue a legal career in a society which lacks an established legal system. Morality of Freedom, 310-11.

xxxiii Consider, for example, Benn's idea of transcendent collective enterprises in Stanley I. Benn A Theory of Freedom (Cambridge: Cambridge University Press, 1988), 218.

${ }^{\text {xxxiv }}$ A fuller account is found in Andrew M. Robinson, Liberalism and Community in a World of Difference, (unpublished doctoral dissertation, University of Western Ontario, 1999). 
${ }^{\mathrm{xxxv}}$ My thinking here is influenced by Kymlicka's account of practical reasoning in Liberalism, Community, and Culture, 51.

xxxvi Chandran Kukathas, "Are There Any Cultural Rights?," Political Theory 20 (1992), 112,

116.

xxxvii Ibid., 110.

xxxviii Consider Frankfurt's "volitional necessity" in Harry G. Frankfurt, "Identification and

Wholeheartedness," in The Importance of What We Care About (Cambridge: Cambridge

University Press), 175.

${ }^{\text {xxxix }}$ The choice of the word reconcile, rather than balance, is intentional. One of the JOURNAL

reviewers alerted me to the fact that "balance" may imply a resolution that is somehow equidistant from the original positions. "Reconciliation," however, especially in cases where practical options are mutually exclusive (expel/don't expel the Protestants), may require a solution that can be justified from both perspectives.

${ }^{\mathrm{xl}}$ This discussion proceeds on a number of assumptions. First, it presupposes an outside community that can determine whether special protection is in fact warranted, and ensure that the principles are respected. The question of whether any community should be in such a position is beyond the scope of this article; that some communities are in such a position, however, is beyond question. Second, it is assumed that the Pueblo would warrant cultural rights on the grounds that the survival of their community is necessary either for their continuing ability to form significant purposes, to pursue them, or both.

${ }^{\text {xli }}$ US Senate, $29,8$.

xlii See, for instance, Taylor's criticism that Kymlicka's argument "doesn't justify measures 
designed to ensure survival [of communities] through indefinite future generations." Charles Taylor, "Politics of Recognition," in Amy Gutmann, ed., Multiculturalism: Examining the Politics of Recognition (Princeton: Princeton University Press, 1994), 41, n. 16.

xliii After the Maori gained real freedom of exit, their identity became "much more a matter of individual choice," Kukathas "Are There Any Cultural Rights?," 117, 128.

${ }^{\text {xliv }}$ Where membership is defined in terms of ascriptive characteristics such as race and ethnicity it may appear problematic because they may deny people access to communities with which they identify, and they seem to rely upon essentialist accounts of identity. Nevertheless, I believe that such definitions could be justified in cases: i) where community members are unable to disentangle their context of values from this identification; ii) where the identification does not inherently entail denial of respect for other people's interest in leading meaningful lives; and iii) where it is extremely unlikely that non-members would choose to identify with the community. In such cases I believe the more repugnant aspects of such definitions would be eliminated over time by the tensions discussed below.

xlv Dozier, "Factionalism at Santa Clara Pueblo," 178-83.

${ }^{x l v i}$ Ralph Linton, "The Distinctive Aspects of Acculturation," in Deward E. Walker, Jr., ed., The Emergent Native Americans (Boston: Little Brown, 1972), 8-9. Linton only considers coerced change, but his points seem to apply to involuntary changes in general. 